ISSN 2657-327X

KULTUROWE

DOI 10.14746/pls.2019.4.5.12

STUDIA

KRAJOBRAZOWE

\title{
Lappland. 2017
}

\section{Wojciech Sternak}

(Faculty of Journalism, Information and Book Studies, University of Warsaw)

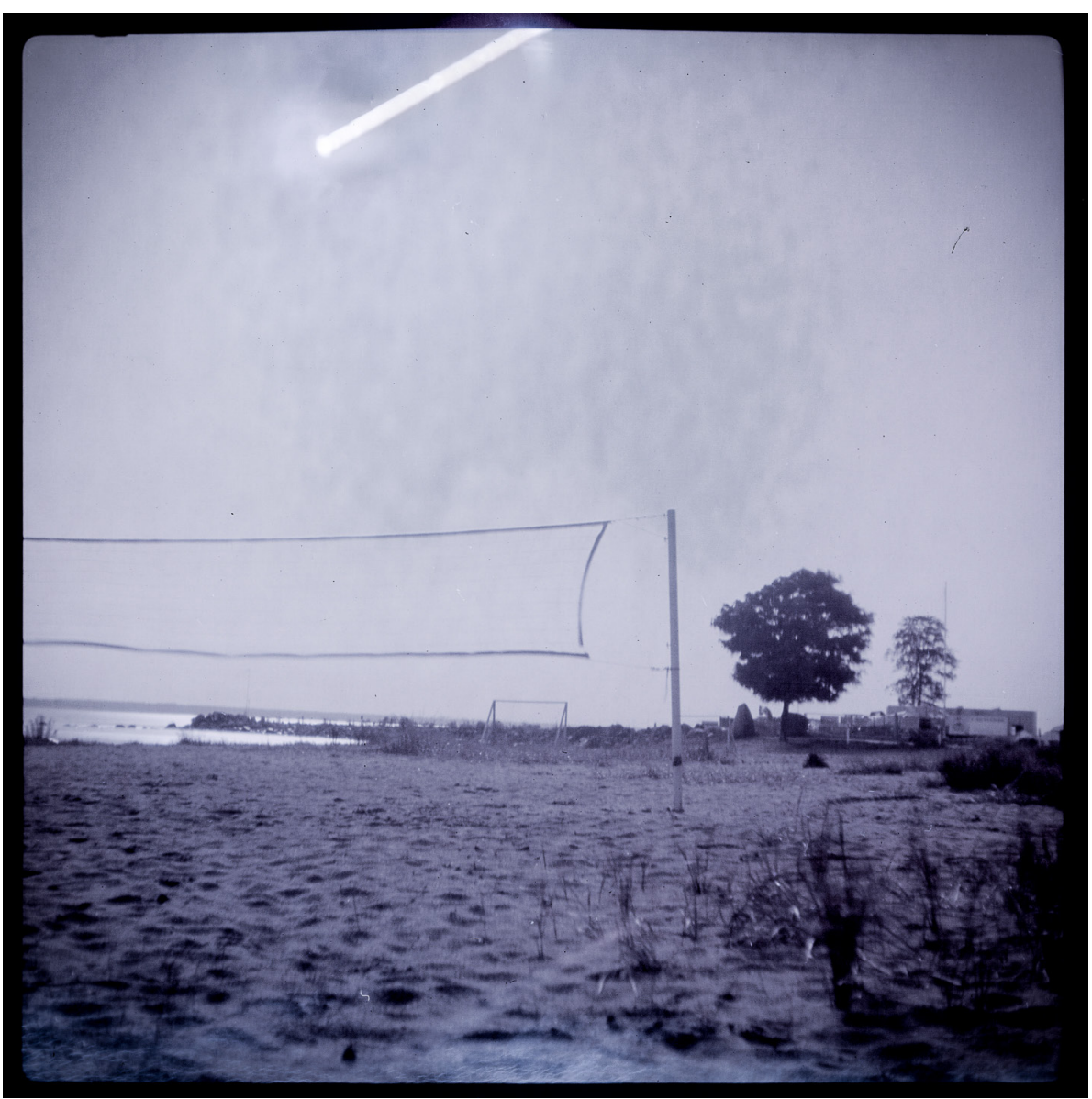




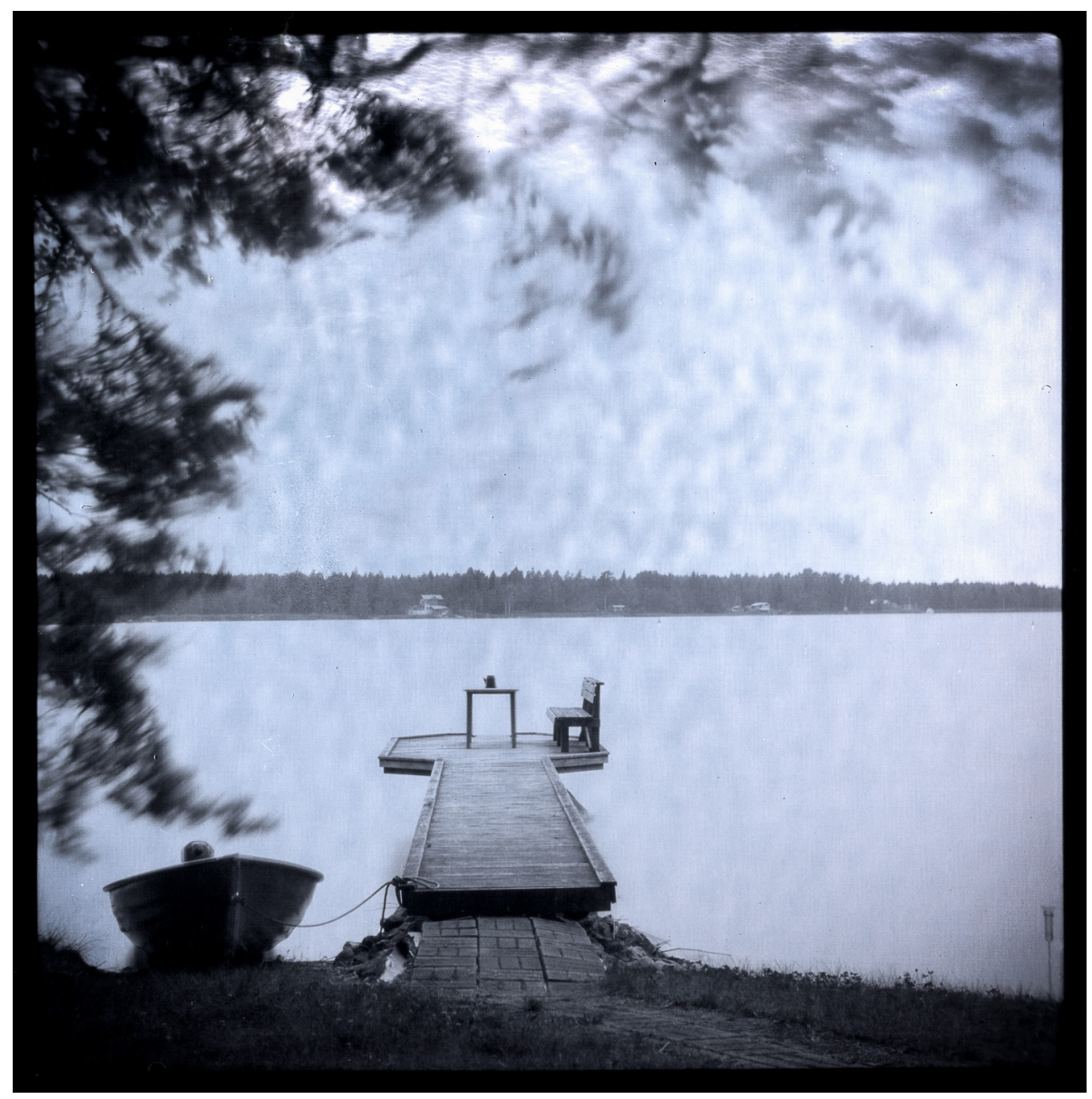




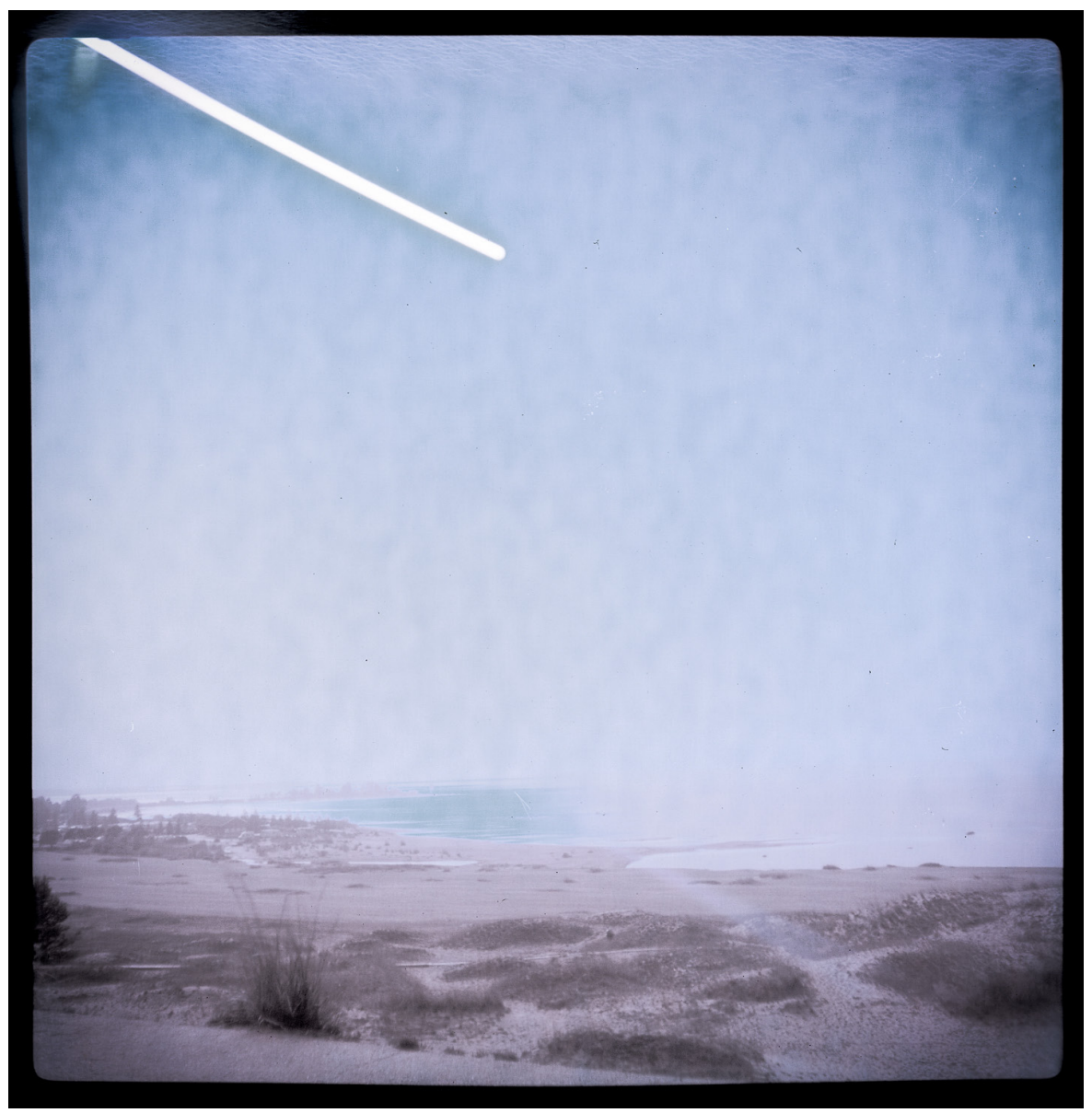




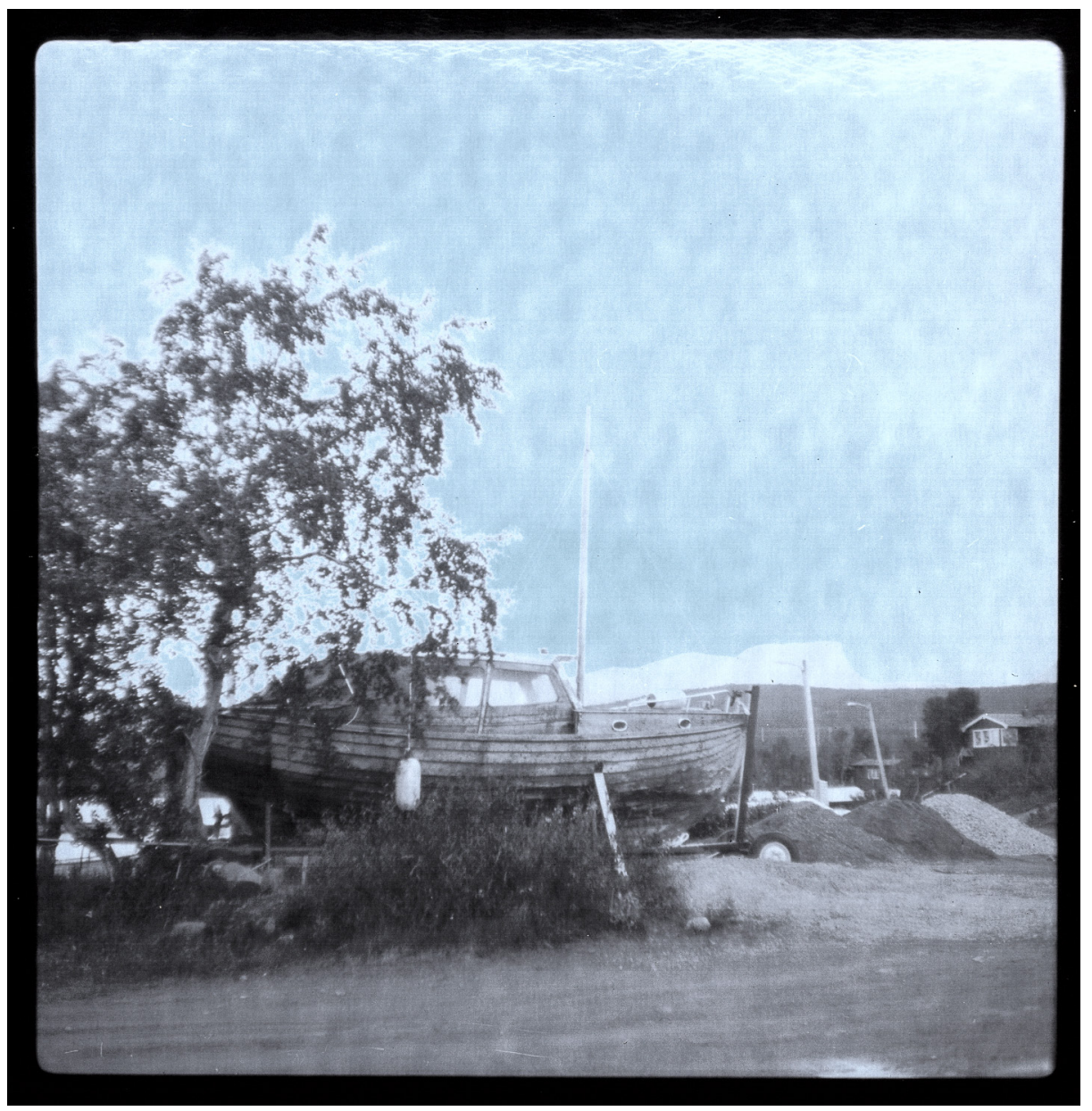




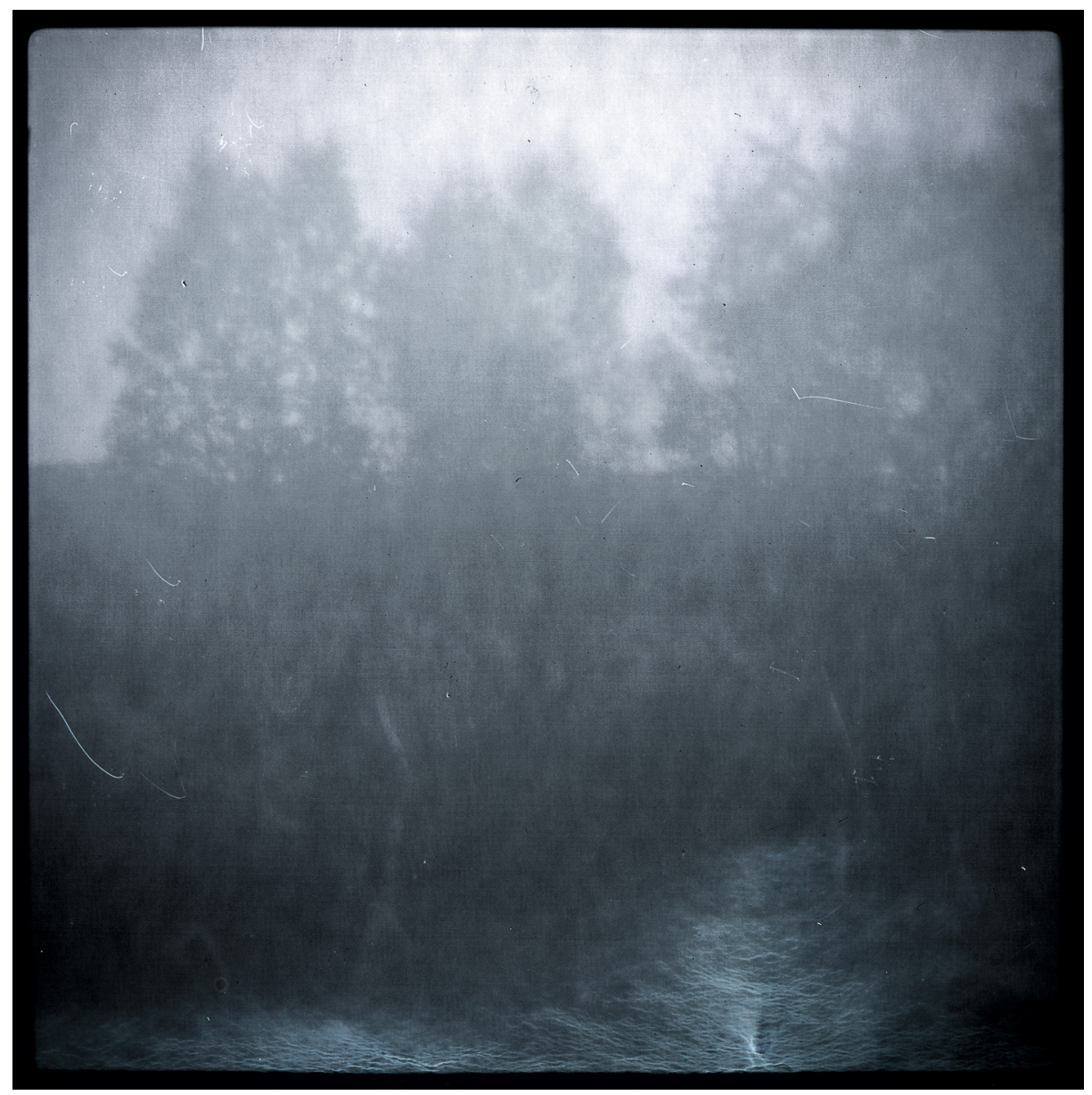




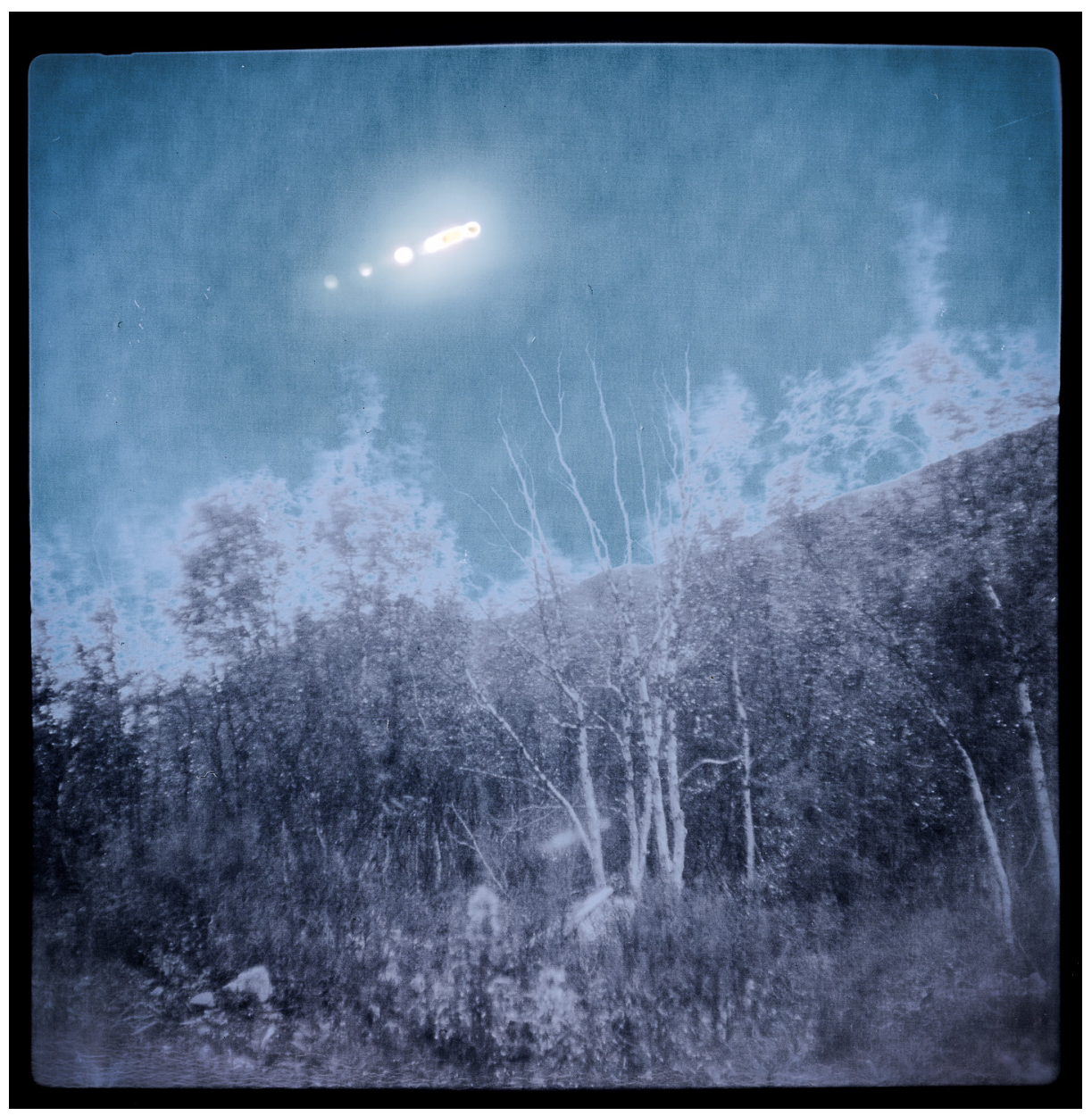




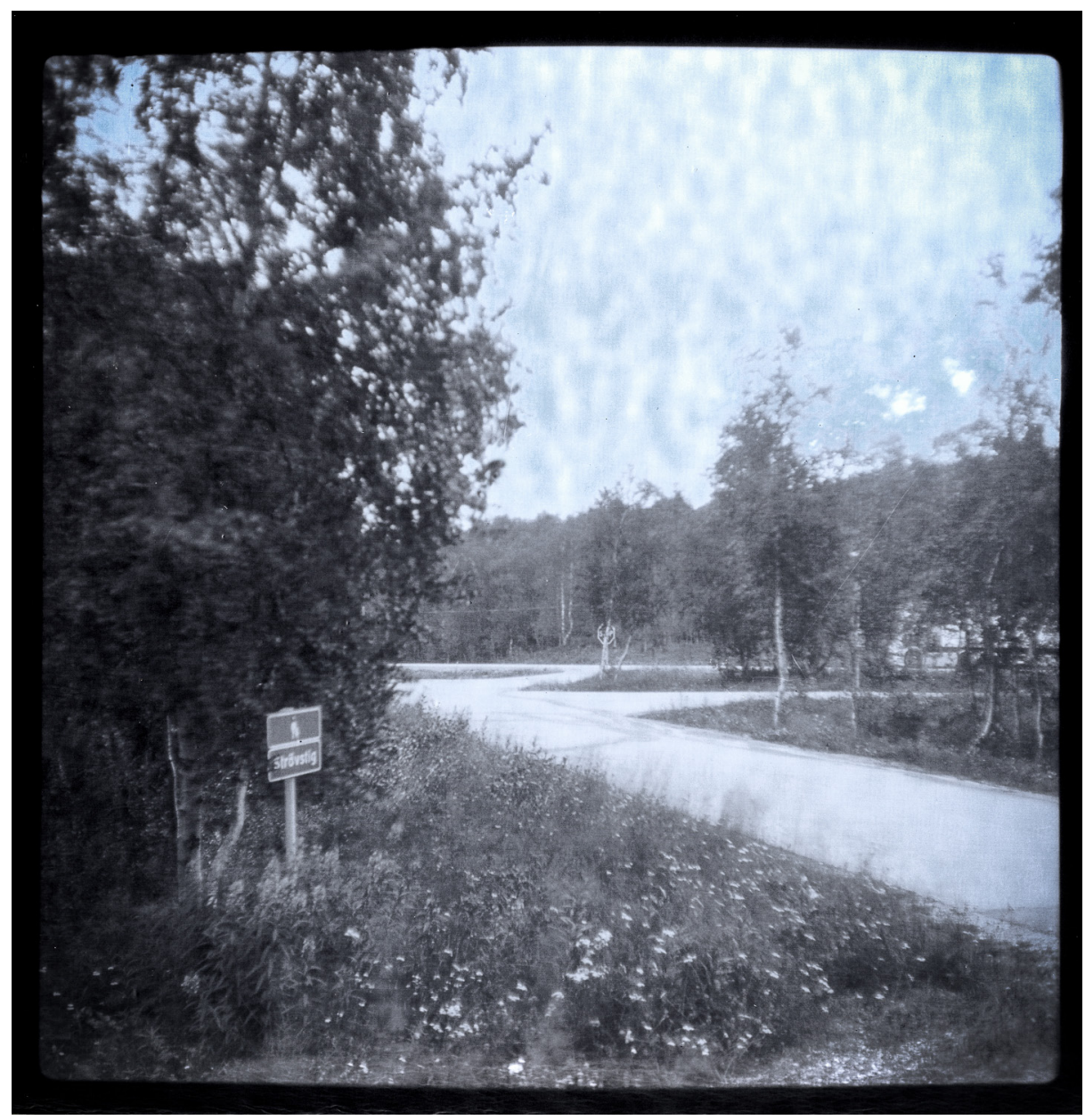




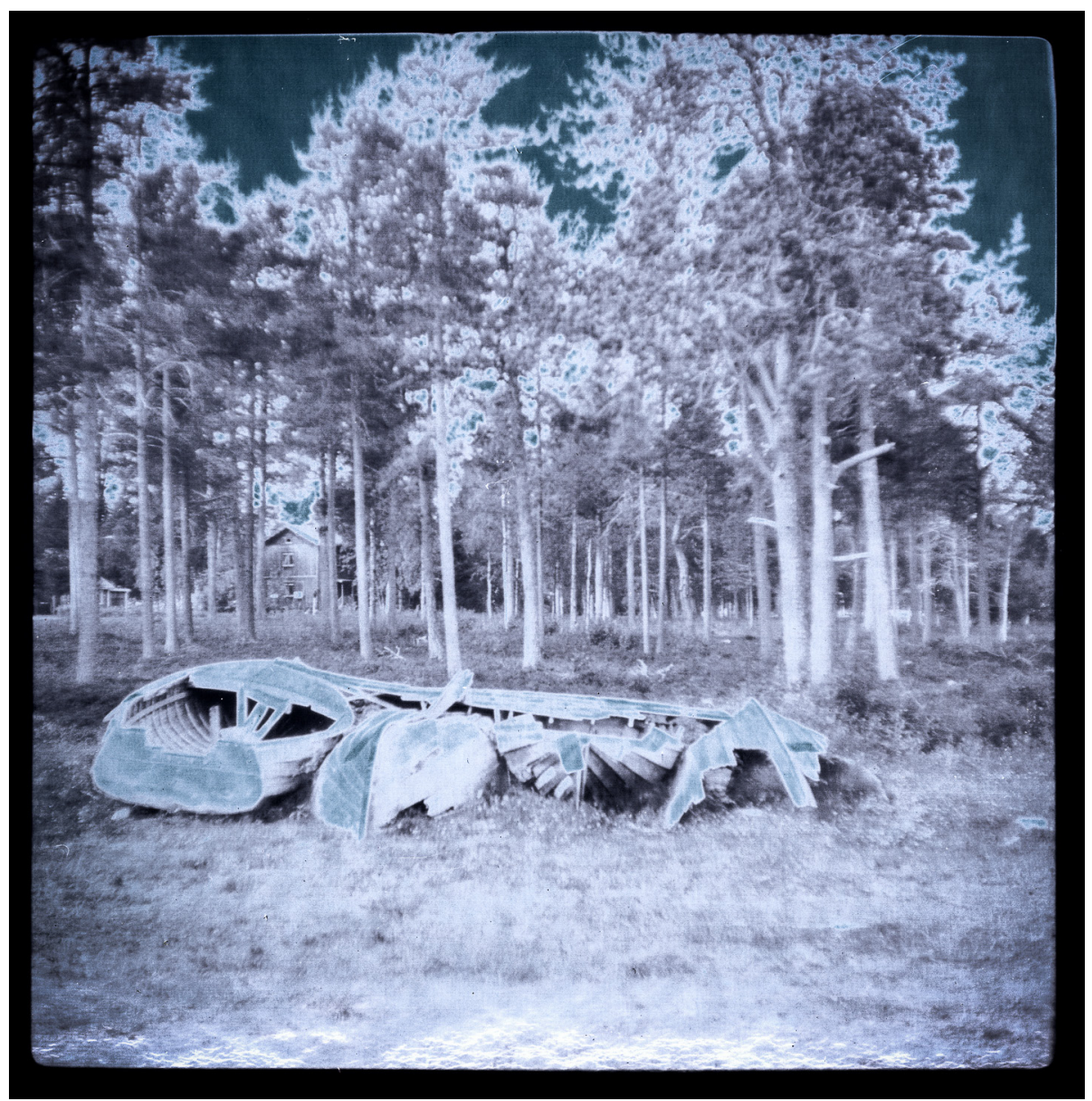




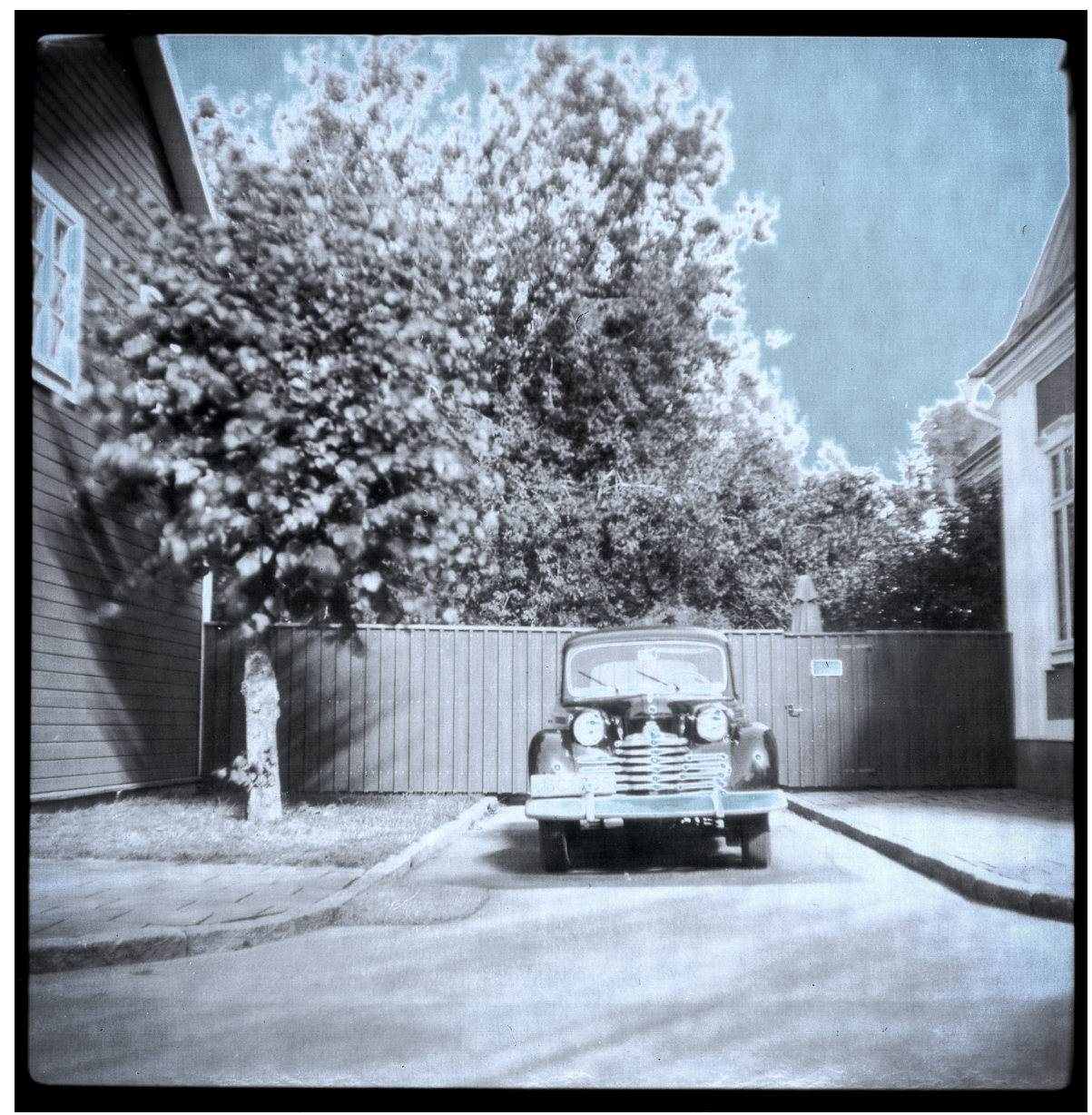


